\title{
Prevalence of Multiple Aetiologies of Abnormal Uterine Bleeding in Perimenopausal Women Using Ultrasound
}

\author{
Fatima Akbar ${ }^{*}$, Akash John ${ }^{2}$, Muhammad Ahmad Naeem ${ }^{3}$, Mariam Kaleem ${ }^{4}, \mathrm{Abid} \mathrm{Ali}^{5}$ \\ ${ }^{1}$ Medical Imaging Doctor (MID), Department of Radiology Sciences and Medical Imaging, the University of Lahore, Gujrat, Pakistan \\ ${ }^{2,3}$ Lecturer, Department of Radiology Sciences and Medical Imaging, the University of Lahore, Gujrat, Pakistan \\ ${ }^{4}$ Medical Imaging Doctor (MID), Department of Radiology Sciences and Medical Imaging, the University of Lahore, Gujrat, Pakistan \\ ${ }^{5}$ Associate Professor, Department of Allied Health Sciences, University of Lahore, Gujrat, Pakistan
}

\section{Article History}

Received: 13.03 .2021

Accepted: 23.04 .2021

Published: 30.04 .2021

Journal homepage:

https://www.easpublisher.com

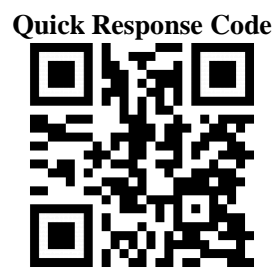

Abstract: Background: Abnormal uterine bleeding is a leading cause of healthcare problems for women, their families, and society in general with an estimated prevalence of $90 \%$ in perimenopausal women. The wider accessibility of ultrasonography allows faster diagnosis of different causes of abnormal uterine bleeding, helping gynaecologists in planning an effective early management for patients. Objective: To find prevalence of different causes of abnormal uterine bleeding using ultrasonography as a diagnostic tool in perimenopausal women. Material and method: This study was conducted at government hospital, Sialkot, Pakistan, on 100 peri-menopausal female patients of 40-55 years of age who attended the hospital OPD with the complaint of abnormal uterine bleeding during the period of August 2020 to February 2021. Results: Majority of the perimenopausal women observed were found in the age group of 40-44 years (50\%). Most of the peri-menopausal women were multi-parous with mean parity of 4 . Menorrhagia (43\%) was the most common patient complaint in peri-menopausal women followed by metrorrhagia in $21 \%$ and menometrorrhagia in $13 \%$. On ultrasound, fibroids were the most frequent findings diagnosed in $24 \%$ of the sample population, endometrial hyperplasia in 17\% and PID in 14\%. Conclusion: For abnormal uterine bleeding in peri-menopausal women, ultrasonography should be considered as a primary imaging tool as it has proven to be an excellent, inexpensive, non-invasive and safe imaging modality to rule out any structural abnormality.

Key words: Abnormal Uterine Bleeding, Menorrhagia, Ultrasonography, Perimenopause, Metrorrhagia.

Copyright (C) 2021 The Author(s): This is an open-access article distributed under the terms of the Creative Commons Attribution 4.0 International License (CC BY-NC 4.0) which permits unrestricted use, distribution, and reproduction in any medium for non-commercial use provided the original author and source are credited.

\section{INTRODUCTION}

Abnormal uterine bleeding is referred to as any alteration in the frequency, length, regularity or flow rate of the usual menstrual cycle $[1,2]$. The unusual uterine bleeding involves menorrhagia (heavy menstrual bleeding), metrorrhagia (intermenstrual bleeding), menometrorrhagia (midcycle spotting), Oligomenorrhoea, polymenorrhoea, unstable uterine bleeding, and abnormal acute uterine bleeding [3, 4] The history of uterine bleeding is important in distinguishing between regular and irregular uterine bleeding [5]. Abnormal uterine bleeding indicates not only how much blood is lost, but also how much it affects a woman's daily life [2].
Peri-menopause is the period between normal menstruation and menopause [6,7]. It is believed to begin two to eight years before the last menstruation and lasts until menopause [8,9]. The age at which perimenopause begins, its duration and frequency of bleeding are all extremely variable [10]. It isn't a disease unless there are complications, and it doesn't necessarily require medical attention. Hormonal changes are also correlated to symptoms, which has a significant effect on women's quality of life. Various clinical signs, such as hot flushes and menstrual irregularities, also signify the beginning of menopause [6]. Peri-menopause usually occurs in women between the ages of 40-58 years, with an average age of 47.5 year for menstrual disturbances [11]. Perimenopause 
lasts around 5 years on average, but symptoms may begin as early as 8 years before the final menstrual period (FMP) [1].

Every woman's peri-menopause may vary. Women in the peri-menopausal stage can experience mood changes, sleep disturbances, and sexual issues, with irregular menstruation being a common symptom $[9,12]$. Some of the common symptoms associated withn perimenopause may include abnormal menstrual bleeding, moderate or irregular spotting, spontaneous and heavy menstrual bleeding, varying menstrual period than in the past, hot flashes, difficulty sleeping, night sweating, temperament fluctuations, loss of libido, and changes in sexual desires [9]. Perimenopausal symptoms may occur up to 8 years before the last menstrual period. Few women will experience numerous symptoms, while others will experience none at all [10].

The PALM-COEIN classification scheme is used to differentiate between structural and nonstructural factors of abnormal uterine bleeding [13, 14]. PALM-COEIN stands for uterine or cervical polyps, adenomyosis, leiomyomas, malignancy and hyperplasia, coagulopathy, ovulatory problems, endometrial abnormalities, iatrogenic and others not discovered yet, according to the International Federation of Gynecology and Obstetrics [6, 8]. It is important to perform a thorough examination of patients with irregular uterine bleeding in order to rule out carcinomas or atypical hyperplasia and to diagnose the accurate cause of bleeding so that effective management can be obtained $[10,15]$.

Ultrasonography may be used to distinguish between structural and non-structural anomalies in PALM-COEIN. Ultrasound is a cost-effective, noninvasive, compact, and efficient modality [16]. Because of its increased availability, rising number of gynaecological disorders can now be diagnosed and handled effectively in the workplace [10]. It assists in assessing the morphology of the uterus as well as the connection between the adjacent pelvic structures. The innovation of ultrasound has played a key role in identifying the multiple aetiologies of abnormal uterine bleeding, enabling gynaecologists and surgeons to plan appropriate medical treatment and, if necessary, surgical procedures [5]. Ultrasound is the 2nd most frequent diagnostic imaging modality after traditional $\mathrm{x}$ ray radiography, with accuracy in the millimetre range for frequencies in clinical use that can be significantly enhanced if the frequency is amplified $[16,17]$.

Abnormal uterine bleeding has a negative impact on women's health and wellbeing around the world, and it affects a large number of women who seek help for gynaecological problems. Owing to hormonal shifts, women entering menopause are more prone to developing endometrial carcinomas. Most of these patients may be suffering from an endometrial disease that necessitates immediate medical treatment. Screening for perimenopausal endometrium with irregular uterine bleeding before menopause will aid in early management.

\section{Material ANd Method}

This is a cross-sectional Descriptive study conducted at Allama Iqbal Memorial Teaching Hospital and Govt. Sardar Begum Teaching Hospital, Sialkot, Pakistan, during the period of August 2020 to February 2021. The study population includes the perimenopausal female patients of 40-55 years of age who attended the hospital OPD with the complaint of abnormal uterine bleeding. A total of 100 perimenopausal women were observed for this study. A data collection performa sheet that had been designed especially for this study was used to collect patient's data including age, parity, clinical history, chief complaint or symptoms. Trans-abdominal scans and wherever required trans-vaginal ultrasound was performed. All of the patients were briefed about the imaging protocol of ultrasonography and gave their informed consent for the study. Pelvic scans were performed scans were performed using anultrasound machine (Toshiba Aplio XU Ultrasound Machine).

\section{Statistical Analysis}

Perimenopausal women with abnormal uterine bleeding were evaluated by inserting the information needed on a specially designed data collection sheet. The Statistical package of Social Sciences (SPSS) version 22 was used to analyze the data. The data was presented in the form of tables and pie charts.

\section{RESUltS}

In this sample of 100 peri-menopausal women, a maximum number of patients were observed in the age group of 40-44 years accounting for $(50 \%), 34 \%$ in 45-50 years while only $16 \%$ were in $50-54$ years age group (Chart 1). Most of the women with abnormal uterine bleeding were multi-parous $(35 \%)$ having less than 3 children followed by $33 \%$ having parity 3-4 and $32 \%$ with parity greater than 4 (Table 1 ). Most of the females with abnormal uterine bleeding presented with the chief complaint of menorrhagia (43\%), metrorrhagia $(21 \%)$, menometrorrhagia $(13 \%)$ and polymenorrhea in $14 \%$, postcoital bleeding in $2 \%$ and others in $3 \%$ (Chart 2 ). On ultrasonography $24 \%$ of the patients had normal findings with no structural abnormality, however fibroids were the most frequent finding diagnosed in $25 \%$, endometrial hyperplasia in $17 \%$ and PID in $14 \%$ (Table 2). Most of the patients with the complaint of metrorrhagia were found to have structural abnormality in contrast to the patients having complaint of menorrhagia. 


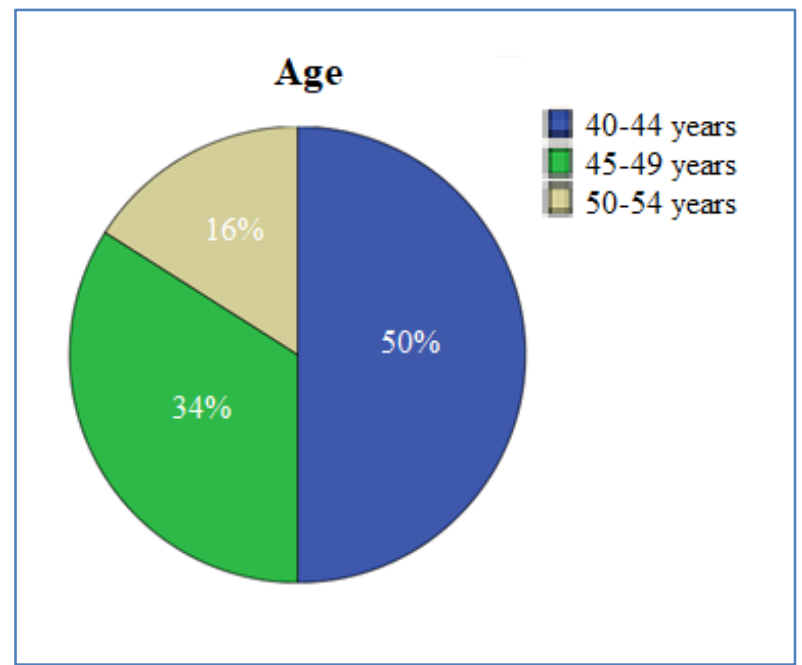

Chart-1: Distribution of cases according to patient age

Table-1: Distribution of cases according to their parity

\begin{tabular}{|l|l|l|}
\hline Parity & No. of women & Percentage \\
\hline$<\mathbf{3}$ & 35 & $35 \%$ \\
\hline $\mathbf{3 - 4}$ & 33 & $33 \%$ \\
\hline$>\mathbf{4}$ & 32 & $32 \%$ \\
\hline Total & 100 & $100 \%$ \\
\hline
\end{tabular}

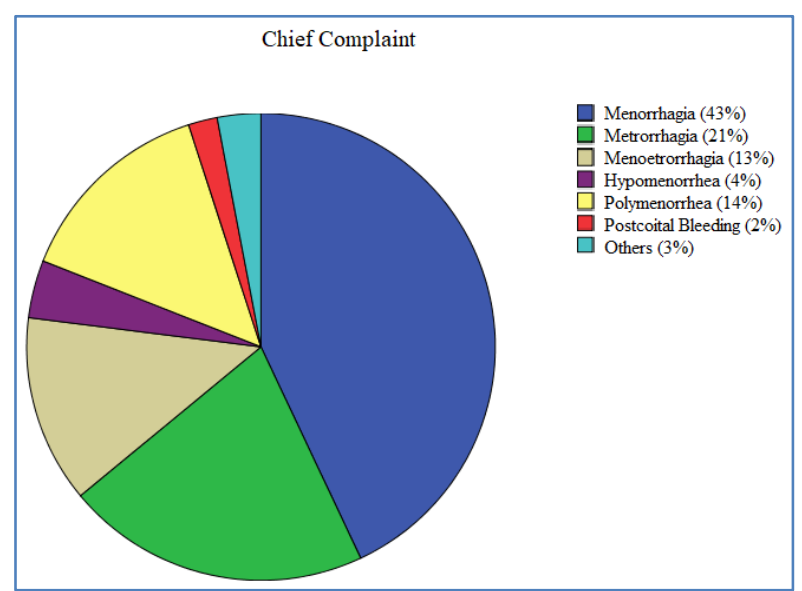

Chart-2: Distribution of cases according to patient complaints

Table-2: Distribution of cases according to Ultrasound Findings

\begin{tabular}{|l|l|l|}
\hline Ultrasound Findings & $\begin{array}{l}\text { No. of } \\
\text { women }\end{array}$ & Percentage \\
\hline Normal & 24 & $24 \%$ \\
\hline $\begin{array}{l}\text { Endometrial } \\
\text { hyperplasia }\end{array}$ & 17 & $17 \%$ \\
\hline Endometrial Atrophy & 6 & $6 \%$ \\
\hline Fibroids & 25 & $25 \%$ \\
\hline PID & 14 & $14 \%$ \\
\hline Endometrial Polyp & 9 & $9 \%$ \\
\hline Endocervical Polyp & 2 & $2 \%$ \\
\hline Forgotten IUCD & 3 & $3 \%$ \\
\hline Total & 100 & $100 \%$ \\
\hline
\end{tabular}

\section{DISCUSSION}

Abnormal uterine bleeding is a significant health issue for women in peri-menopausal age [5, 10]. However, the invention of ultrasonography has enabled us to precisely diagnose the different causes of abnormal uterine bleeding in its acute form which helps in management of the condition without any delay [16]. In this study, ultrasound was observed to be more precise in diagnosing structural abnormalities like fibroids, PID, polyps and endometrial thickness.

In our study, the majority of patients were in the range of $40-44$ years of age comprising $50 \%$ of total cases followed by $34 \%$ in $45-50$ years while only $16 \%$ were in 50-54 years age group (as shown in chart 1). Most of the patients who complained about abnormal uterine bleeding were going through menopausal transition. These findings are similar to a study carried out by Baghel et al. in 2014 in which $(57 \%)$ of the women were in the age group 40-45 years [8]. Almost similar results were seen in study conducted by Bhosle and Fonseca which reported high proportion $(76.1 \%)$ of peri-menopausal women in the age range of 40- 45 years with abnormal uterine bleeding [18].

The majority of patients in our study who complained of abnormal uterine bleeding were multiparous, with parity $<3$ accounting for $35 \%$ of cases, parity 3-4 accounting for $33 \%$ and parity $>4$ accounting for the least i.e; 32\% (Table 1). The results are comparable to the study conducted by Sakshi Daga, Suresh Phatak in which $76.80 \%$ of cases accounting for parity $2[8]$.

Menorrhagia was the most prevalent presenting complaint in our study accounting for $43 \%$ of cases, followed by metrorrhagia in $21 \%$, menometrorrhagia in $13 \%$, Polymenorrhea in $14 \%$, postcoital bleed in accounting for the least in $2 \%$ of the cases observed (Chart 2). Studies conducted by bhosle and fonseca and Baghel et al had 53\% and 52\% of the patients with complaint of menorrhagia $[8,18]$. Study conducted by Damle et al. also had $48.86 \%$ of the patients with patient complaint of menorrhagia [19].

In our study, about $24 \%$ of the patients who appeared to gynecology department with the complaint of abnormal uterine bleeding had normal findings on ultrasonography (Table 2). Similarly in a prospective study conducted by Jain and Chakraborty, about $48 \%$ of the peri-menopausal women were having normal findings [20]. The majority of the patients in our study had been diagnosed with a medical condition that required immediate treatment. 


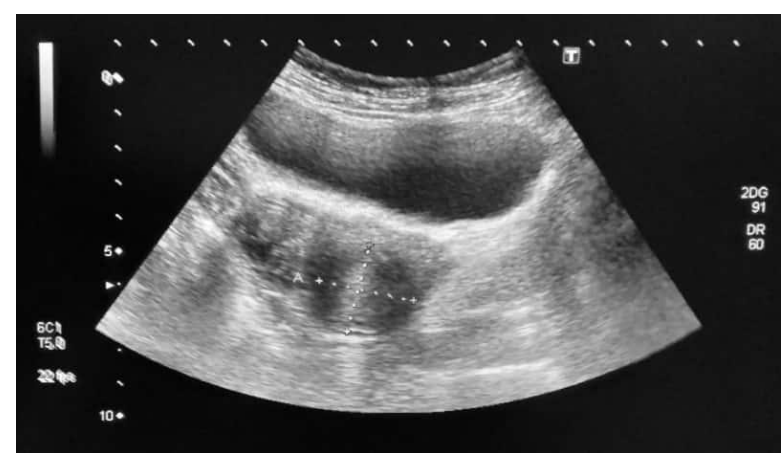

Fig-1: Grayscale imaging showing a uterine fibroid (measuring $2.8 \times 2.8 \mathrm{~cm}$ ) seen at cervix.

In present study, fibroids were reported to be the most common organic cause of abnormal uterine bleeding, comprising $25 \%$ of the cases (Figure 1). A study conducted by Sakshi Daga and Suresh Phatak in 2020 concluded fibroids as the major cause of abnormal uterine bleeding seen in $39.44 \%$ of the cases [8]. Bhosle and Fonseca also revealed fibroids as the most frequently seen abnormality accounting for $47.3 \%$ on ultrasonography in peri-menopausal women [8].

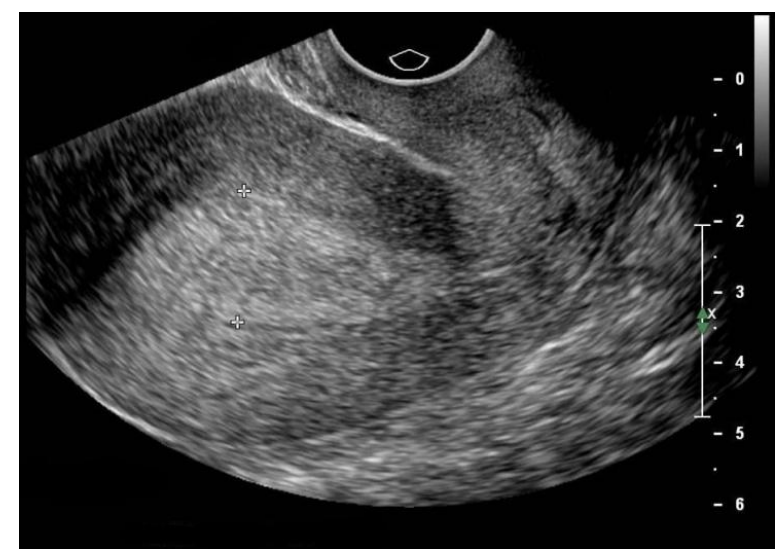

Fig-2: Transvaginal Ultrasound showing thickened endometrium (measuring $20 \mathrm{~mm}$ ) suggestive of endometrial hyperplasia

In our study, endometrial hyperplasia was observed in $17 \%$ of the sample population (Figure 2). Similar findings were observed in a study conducted by Jain and Chakraborty in which endometrial hyperplasia was found in $22 \%$ of the cases [20]. In assessing endometrial hyperplasia and other intrauterine pathology, trans-vaginal sonography has a moderate diagnostic precision [21].

\section{CONCLUSION}

This study concludes that ultrasound should be considered as the primary imaging modality in perimenopausal women with the symptoms of abnormal uterine bleeding as it is cheap, safe, widely available, painless and non-invasive. Ultrasound has high sensitivity to rule out any endometrial as well as pelvic pathology which might be missed by clinical assessment. Each case of perimenopausal bleeding requires a thorough evaluation to precisely determine the root cause of the bleeding and establish a correct diagnosis as early as possible. This aids gynecologists in planning an effective treatment for the patients without any delay aiding in the reduction of distress of patients.

\section{Ethical considerations}

The rules and regulations set by the ethical committee of university of Lahore were followed while conducting this current research and the rights of the research participants was respected.

\section{Confidentiality of data}

A written informed consent was taken from all the patients having abnormal uterine bleeding. All collected data will be kept confidential for research purpose only.

\section{Informed consent and right to privacy}

Patients were given the right to withdraw their information in any step of data collection. Everything is in confidentiality and all the things that were mentioned in the article are with the permission of every single person which is considered in this article.

\section{REFERENCES}

1. Singh S, Best C, Dunn S, Leyland N, Wolfman WL, Wolfman W, Allaire C, Awadalla A, Heywood M, Lemyre M, Marcoux V. Abnormal uterine bleeding in pre-menopausal women. Journal of Obstetrics and Gynaecology Canada. 2013 May 1;35(5):473-5.

2. Verma U, Garg R, Singh S, Yadav P, Rani R. Diagnostic approach in perimenopausal women with abnormal uterine bleeding. Journal of SAFOMS. 2014;2(1):12.

3. Nargis N, Karim I, Sarwar KB. Abnormal uterine bleeding in perimenopausal age: different causes and its relation with histopathology. Bangladesh Journal of Medical Science. 2014;13(2):135-9.

4. Palep-Singh M, Prentice A. Epidemiology of abnormal uterine bleeding. Best Practice \& Research Clinical Obstetrics \& Gynaecology. 2007;21(6):887-90.

5. Marret H, Fauconnier A, Chabbert-Buffet $\mathrm{N}$, Cravello L, Golfier F, Gondry J, Agostini A, Bazot M, Brailly-Tabard S, Brun JL, De Raucourt E. Clinical practice guidelines on menorrhagia: management of abnormal uterine bleeding before menopause. European Journal of Obstetrics \& Gynecology and Reproductive Biology. 2010 Oct 1;152(2):133-7.

6. Madhra M, Fraser IS, Munro MG, Critchley HO. Abnormal uterine bleeding: advantages of formal classification to patients, clinicians and researchers. Acta obstetricia et gynecologica Scandinavica. 2014;93(7):619-25.

7. Bradlev LD. 10 Investigation of Abnormal Uterine Bleeding in Premenopausal Women. Hysteroscopy: 
Office Evaluation and Management of the Uterine Cavity. 2008:95.

8. Daga S, Phatak S. Sonography evaluation of abnormal uterine bleeding in perimenopausal women with pathological correlation. Journal of Datta Meghe Institute of Medical Sciences University. 2019;14(4):288.

9. McNamara M, Batur P, DeSapri KT. Perimenopause. Annals of internal medicine. 2015;162(3):ITC1-ITC16.

10. Goldstein S, Lumsden M. Abnormal uterine bleeding in perimenopause. Climacteric. 2017;20(5):414-20.

11. Byna P, Siddula S, Kolli S, Shaik MV. Histopathological correlation of abnormal uterine bleeding in perimenopausal women. International Journal of Reproduction, Contraception, Obstetrics and Gynecology. 2015;4(6):1876.

12. Kotdawala P, Kotdawala S, Nagar N. Evaluation of endometrium in peri-menopausal abnormal uterine bleeding. Journal of mid-life health. 2013;4(1):16.

13. Betha K, Malavatu L, Talasani S. Distribution of causes of abnormal uterine bleeding using new FIGO classification system-PALM COEIN: a rural tertiary hospital based study. Int $\mathrm{J}$ Reprod Contraception, Obstet Gynecol. 2017;6:3523.

14. Kotagasti T. Prevalence of different menstrual irregularities in women with abnormal uterine bleeding (AUB)-an observational study. International Journal of Current Research and Review. 2015;7(10):66.
15. Munro MG, Critchley HO, Fraser IS. The FIGO systems for nomenclature and classification of causes of abnormal uterine bleeding in the reproductive years: who needs them? American journal of obstetrics and gynecology. 2012;207(4):259-65.

16. Shung KK. Diagnostic ultrasound: Past, present, and future. J Med Biol Eng. 2011;31(6):371-4.

17. Organization WH. Research on the menopause: report of a WHO scientific group [meeting held in Geneva from 8 to 12 December 1980]: World Health Organization; 1981.

18. Bhosle A, Fonseca M. Evaluation and histopathological correlation of abnormal uterine bleeding in perimenopausal women. Bombay Hosp J. 2010;52(1):69-72.

19. Damle RP, Dravid N, Suryawanshi KH, Gadre AS, Bagale PS, Ahire N. Clinicopathological spectrum of endometrial changes in peri-menopausal and post-menopausal abnormal uterine bleeding: A 2 years study. Journal of clinical and diagnostic research: JCDR. 2013;7(12):2774.

20. Jain M, Chakraborty S. Evaluation of abnormal uterine bleeding with transvaginal sonography. International Journal of Reproduction, Contraception, Obstetrics and Gynecology. 2017;6(7):2794-9.

21. Getpook C, Wattanakumtornkul S. Endometrial thickness screening in premenopausal women with abnormal uterine bleeding. Journal of Obstetrics and Gynaecology Research. 2006;32(6):588-92.

Cite This Article: Fatima Akbar et al (2021). Prevalence of Multiple Aetiologies of Abnormal Uterine Bleeding in Perimenopausal Women Using Ultrasound. EAS J Radiol Imaging Technol, 3(2), 102-106. 